\title{
Fuzzy logic positioning system of electro-pneumatic servo-drive
}

\author{
Jakub E. Takosoglu1, Ryszard F. Dindorf1,2 \\ and Pawel A. Laski ${ }^{1}$ \\ ${ }^{1}$ Kielce University. of Technology \\ ${ }^{2}$ AGH University of Science and Technology, Krakow \\ Poland
}

\section{Introduction}

Development of automation and robotization in manufacturing process stimulates interest in pneumatic servo-systems whose advantages include low manufacturing costs, high dynamics and reliability (Situm et al., 2004). Unsatisfactory positioning accuracy of multiaxis pneumatic servosytems considerably reduces their application in manipulating machines, manipulators and robots. Rapid advance in parallel pneumatic manipulators imposes a lot of demands on controllers of pneumatic servo-drive concerning positioning accuracy, resistance to alternating parameters of state and disturbing signals (Dindorf et al., 2005; Takosoglu \& Dindorf, 2005; Schulte \& Hahn, 2004). The problem of positioning accuracy of servo-pneumatic systems is difficult to solve when no sufficient information on the process of conversion of the compressed gas energy into mechanical energy of pneumatic cylinder is available (Zhu, 2006; Takosoglu, 2005). Because of that, new control methods based on artificial intelligence, for example, fuzzy logic are introduced (Schulte \& Hahn, 2004; Renn \& Liao, 2004; Dindorf \& Takosoglu, 2005). In traditional control systems of pneumatic servo-drives control algorithms are designed intuitively on the basis of operator's experience. In fuzzy control the knowledge coded in knowledge base is the result of experience, intuition as well as theoretical and practical understanding of control system dynamics which in this case is the dynamics of pneumatic servosystems. Thanks to fuzzy logic the operator's knowledge can be represented by means of mathematical operations. Fuzzy control enables moving from qualitative to quantitative control of pneumatic servodrive. Application of fuzzy controller makes control of multiaxial pneumatic sevosystems possible in manipulators and robots of various kinematic structures: series, parallel or hybrid series/parallel. Advancements in software for rapid prototyping in real time and in hardware-in-the-loop simulations enable to construct and test positioning fuzzy control (Bucher \& Balemi, 2006) of pneumatic servo-drives in laboratory conditions. Such an approach minimizes the design costs of control systems of pneumatic servo-drives. Pneumatic servo-drives with teaching/playback control system have considerable practical significance, especially in the control of manipulating machines, manipulators, industrial robots as well as rehabilitation and physiotherapy manipulators. 
Pneumatic servo-cylinders used in multi-axis electro-pneumatic systems and referred to as pneumatic axes perform operations and function as supporting structure. Cartesian manipulators with pneumatic axes connected in series are classified as open-loop chain kinematic mechanisms. In serial kinematic chain elastic strains accumulate on particular pneumatic axes, which lowers the positioning accuracy of pneumatic manipulators. Parallel mechanism is a closed-loop mechanism in which the moving platform is connected to the fixed base by independent kinematic chains. Kinematic structure in the form of a closedloop chain finds application in parallel kinematic robot (PKR) and parallel kinematic machine (PKM). Manipulators based on parallel kinematics structure can achieve better accuracy of repeatability and they can apply larger forces than conventional serial manipulators because of the higher stiffness of their mechanical structure. By using parallel kinematics in machine tools high stiffness and high machine dynamics is achieved. With Stewart-Gough Platform as a base numerous kinematic structures of parallel manipulators (Nonapod, Hexapod, Tripod) and hybrid manipulators (Tricept, Dyna-M, LinaPod) were formed. The names of kinematic structures of parallel manipulators are related to the kind of kinematic joint and the number of degrees of freedom (DoF). To calculate degrees of freedom of parallel manipulators the formula proposed by Tsai is used. The family of parallel manipulators includes translational parallel manipulators (TPM) based on three degrees of freedom (3-DoF) and containing at least one prismatic joint. In the group of 3DoF TPM manipulators the most common are - spatial parallel mechanism of the structure: 3-PUU, 3-UPU, 3-UPS, 3-CPU, 3-PUS, 3-PCRR and planar parallel mechanism of the structure: 3-RPR, 3-PRR. 3-PPR, 3-RRR (Merlet, 2006).

\section{Simulation model of electro-pneumatic servo-system}

The object of research is control system of pneumatic servo-drive which is presented in Fig. 1.

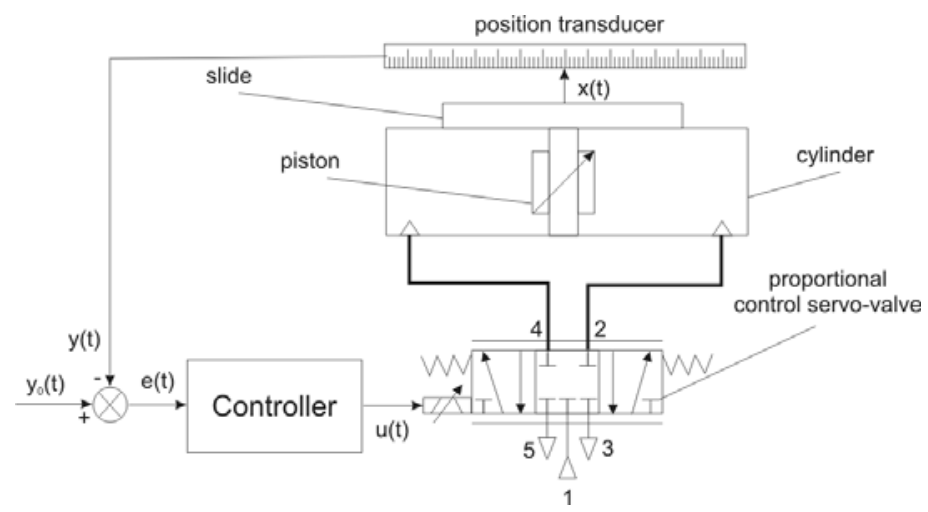

Fig. 1. The diagram of electro-pneumatic servo-drive control system

The controller of pneumatic servo-system processes the position error $e(t)=y_{0}(t)-y(t)$ into voltage signal $u(t)$ in the selenoid of proportional directional control valve controlling the slide of the rodless cylinder, where $y_{o}(t)$ is the input signal, and $y(t)$ the signal generated by displacement transducer of the rodless cylinder's linear slide of $x(t)$ coordinate. The functional model of the analyzed pneumatic servo-drive with rodless cylinder controlled by 
proportional directional control valve is presented in Fig. 2a and Fig. $2 \mathrm{~b}$ and its nonlinear dynamic model is written as the following set of differential equations (Takosoglu \& Dindorf, 2005):

- equation of motion for the piston - slide of rodless cylinder:

$$
\frac{d^{2} x}{d t^{2}}=\frac{1}{M+m}\left\{A \Delta p-\left[f_{l} v+F_{k} \operatorname{sgn}(v)+F_{p r} e^{\left(-\frac{v}{v_{k}}\right)} \operatorname{sgn}(v)+k_{p}|\Delta p|\right]+m g \sin \alpha\right\}^{\prime}
$$

where: $x, v$-displacement and velocity of piston - slide,

$A$-area of piston,

$\Delta p$ - pressure difference between cylinder chambers, $\Delta p=p_{1}-p_{2}$,

$p_{1}, p_{2}-$ absolute pressures in cylinder's chambers,

$M$ - mass of piston and slide,

$f_{l}$ - viscous friction coefficient,

$F_{k}$ - kinetic friction force (Coulomb friction force),

$v_{k}$ - critical value of velocity, characteristic velocity of the Stribeck friction,

$F_{p r}$ - break away force,

$k_{p}$ - friction coefficient dependent upon seal dimensions,

$m$ - initial load mass,

$g$ - acceleration of gravity,

$a$ - servo-motor infliction angle.
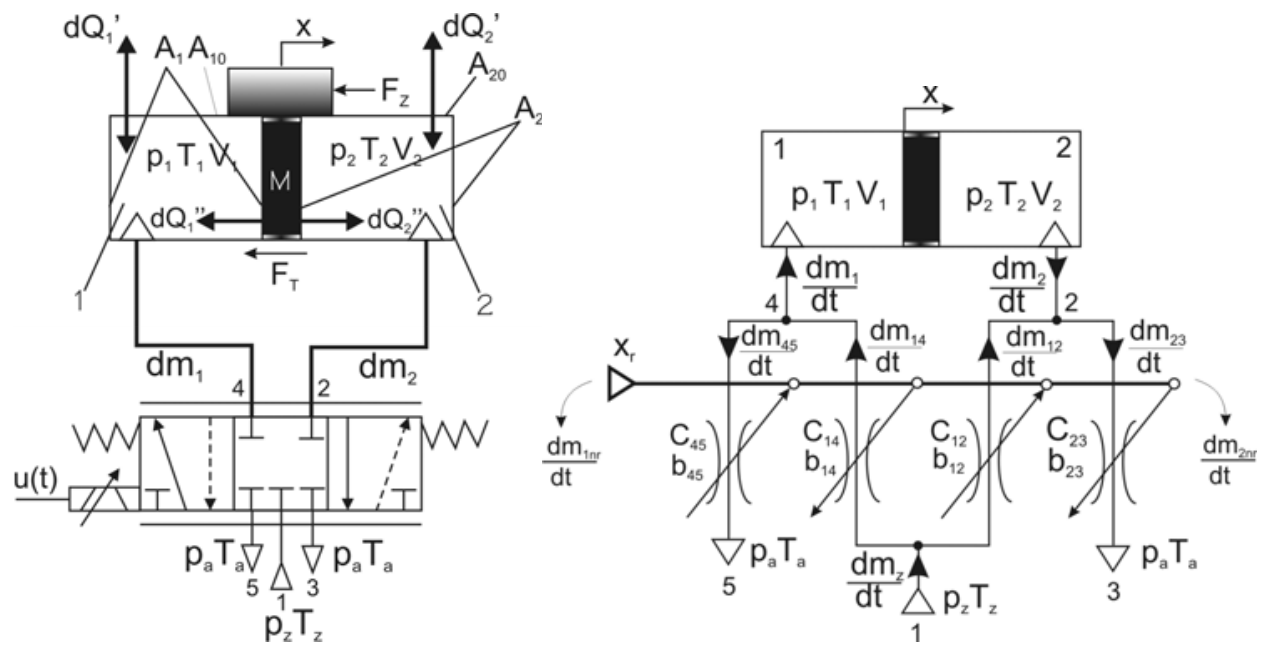

Fig. 2. The diagrams: a) pneumatic rodless cylinder, b) servo-valve system

- equation of motion for the spool of proportional directional control valve:

$$
\frac{d^{2} x_{r}}{d t^{2}}=\frac{1}{m_{r}}\left\{\frac{k_{m}}{R_{c}}\left(u-n B l_{c} v_{r}\right)\left(1-e^{\frac{R_{c}}{L} t}\right)-f_{t} v_{r}-k_{s} x_{r}\right\}
$$


where: $x_{r}, v_{r}$ - displacement and velocity of valve spool,

$m_{r}$ - mass of spool,

$k_{m}$-coefficient of electromechanical force transducer,

$R_{c}$ - resistance of the solenoid,

$u$ - coil voltage,

$n$ - number of coils,

$B$ - magnetic induction,

$l_{c}$ - length of coil,

$L$ - inductance of the solenoid,

$f_{t}$ - coefficient of viscous friction,

$k_{s}$ - spool spring rate.

- equations for pressure in cylinder chambers:

$$
\begin{aligned}
& \frac{d p_{1}}{d t}=\frac{\kappa}{A\left(l_{0}+x\right)}\left\{R \frac{d m_{1}}{d t}-p_{1} A v-\frac{\kappa-1}{\kappa} \alpha\left[A_{10}\left(T_{1}-T_{a}\right)+A\left(T_{1}-T_{2}\right)\right]\right\}, \\
& \frac{d p_{2}}{d t}=\frac{\kappa}{A\left(l+l_{0}-x\right)}\left\{-R \frac{d m_{2}}{d t}+p_{2} A v-\frac{\kappa-1}{\kappa} \alpha\left[A_{20}\left(T_{2}-T_{a}\right)+A\left(T_{2}-T_{1}\right)\right]\right\}
\end{aligned}
$$

where: $\kappa$ - adiabatic exponent,

$l_{0}$ - length of dead zone of the pneumatic cylinder,

$l$ - stroke length of pneumatic cylinder,

$R$ - specific gas constant,

$\alpha$ - overall heat-transfer coefficient,

$T_{1}, T_{2}$ - temperature in cylinder chambers,

$T_{a}$ - ambient temperature,

$A_{10}, A_{20}$ - heat transfer surface,

$\frac{d m_{1}}{d t}, \frac{d m_{2}}{d t}$ - mass flow rate,

- equations for mass flow rate through proportional control valve:

$$
\begin{aligned}
& \frac{d m_{1}}{d t}=C_{14} \rho_{0} \sqrt{\frac{T_{0}}{T_{z}}} p_{z} w_{14}-C_{45} \rho_{0} \sqrt{\frac{T_{0}}{T_{1}}} p_{1} w_{45} \\
& \frac{d m_{2}}{d t}=C_{23} \rho_{0} \sqrt{\frac{T_{0}}{T_{2}}} p_{2} w_{23}-C_{12} \rho_{0} \sqrt{\frac{T_{0}}{T_{z}}} p_{z} w_{12}
\end{aligned}
$$

where: $\rho_{0}$ - air density in the normal reference atmosphere (ANR),

$T_{0}$ - normal ambient temperature,

$p_{z}$ - air supply pressure,

$T_{z}$ - air supply temperature,

$C_{14}, C_{45}, C_{12}, C_{23}$ - sonic conductance consistent with the standard ISO 6358-1989 for critical pressure ratio,

$w_{14}, w_{45}, w_{12}, w_{23}$ - nonlinear flow function (sonic flow and subsonic flow) depending on the pressure ratio and on the critical pressure ratio, 


$$
\begin{aligned}
& w_{14}=\left\{\begin{array}{ccc}
1 & \text { and } & 0 \leq \frac{p_{1}}{p_{z}} \leq b_{12}, \\
1-\left(\frac{\frac{p_{1}}{p_{z}}-b_{14}}{1-b_{14}}\right)^{2} & b_{12} \leq \frac{p_{1}}{p_{z}} \leq 1
\end{array}\right. \\
& w_{45}=\left\{\begin{array}{ccc}
1 & \text { and } & 0 \leq \frac{p_{a}}{p_{2}} \leq b_{45}, \\
1-\left(\frac{\frac{p_{a}}{p_{2}}-b_{45}}{1-b_{45}}\right)^{2} & b_{45} \leq \frac{p_{a}}{p_{2}} \leq 1
\end{array}\right. \\
& w_{12}=\left\{\begin{array}{ccc}
1 & \text { and } & 0 \leq \frac{p_{1}}{p_{z}} \leq b_{12} \\
\sqrt{1-\left(\frac{\frac{p_{1}}{p_{z}}-b_{12}}{1-b_{12}}\right)^{2}} & b_{12} \leq \frac{p_{1}}{p_{z}} \leq 1
\end{array}\right. \\
& w_{23}=\left\{\begin{array}{ccc}
1 & \text { and } & 0 \leq \frac{p_{a}}{p_{2}} \leq b_{23} \\
1-\left(\frac{\frac{p_{a}}{p_{2}}-b_{23}}{1-b_{23}}\right)^{2} & b_{23} \leq \frac{p_{a}}{p_{2}} \leq 1
\end{array},\right.
\end{aligned}
$$

where: $b_{14}, b_{45}, b_{12}, b_{23}$ - critical pressure ratio.

The simulation model of pneumatic servo-drive represented by equations (1) - (8), was used for selection and initial verification of fuzzy controller. The model of pneumatic servo-drive was implemented for Matlab-Simulink package with Fuzzy Logic Toolbox. The block diagram of the model of pneumatic servo-drive with fuzzy controller is presented in Fig. 3.

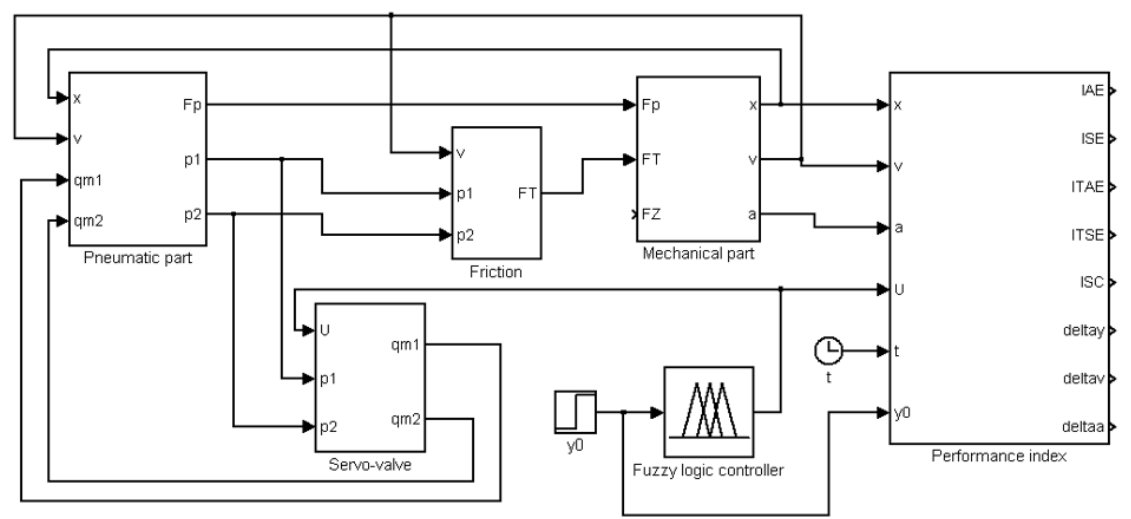

Fig. 3. The simulink block diagram of simulation model of electro-pneumatic servo-drive with fuzzy controller 
Fuzzy PD controller constructed in Fuzzy Logic Tollbox of Matlab Simulink package was suggested for the purpose of controlling pneumatic servo-drive. The pneumatic servo-drive together with fuzzy PD controller constitute a system of MISO type with two inputs: position error $e(t)$ and change of position error $\Delta e(t)$ and one output: proportional valve coil voltage $u(t)$. Output and input signals underwent fuzzification process with regular distribution of 7 fuzzy sets of triangular and trapezoid membership functions) (Takosoglu \& Dindorf, 2005). The knowledgebase rules of fuzzy controller are 49 Mac Vicar-Whelen rules described in the table entered to Fuzzy Logic Toolbox. In the inference process the firing degree was determined by means of MIN operator, implication operator and all the inputs of particular rules were aggregated by MAX operator. In the defuzzyfication process the center-of-gravity-method (COG) was applied. The dialogue window "Rule Viewer" of Fuzzy Logic Toolbox is a kind of diagnostic device which enables tracing which fuzzy rules were activated on particular states of input. It also enables observation of fuzzy system output value. The fuzzy logic controller of PD type was tuned by means of Simulink Response Optimization Toolbox of Matlab-Simulink package.

\section{Research stand}

The view and diagram of the test stand used to conduct experiments on fuzzy logic control of pneumatic servo-drive are presented in Fig. 4 and Fig. 5.

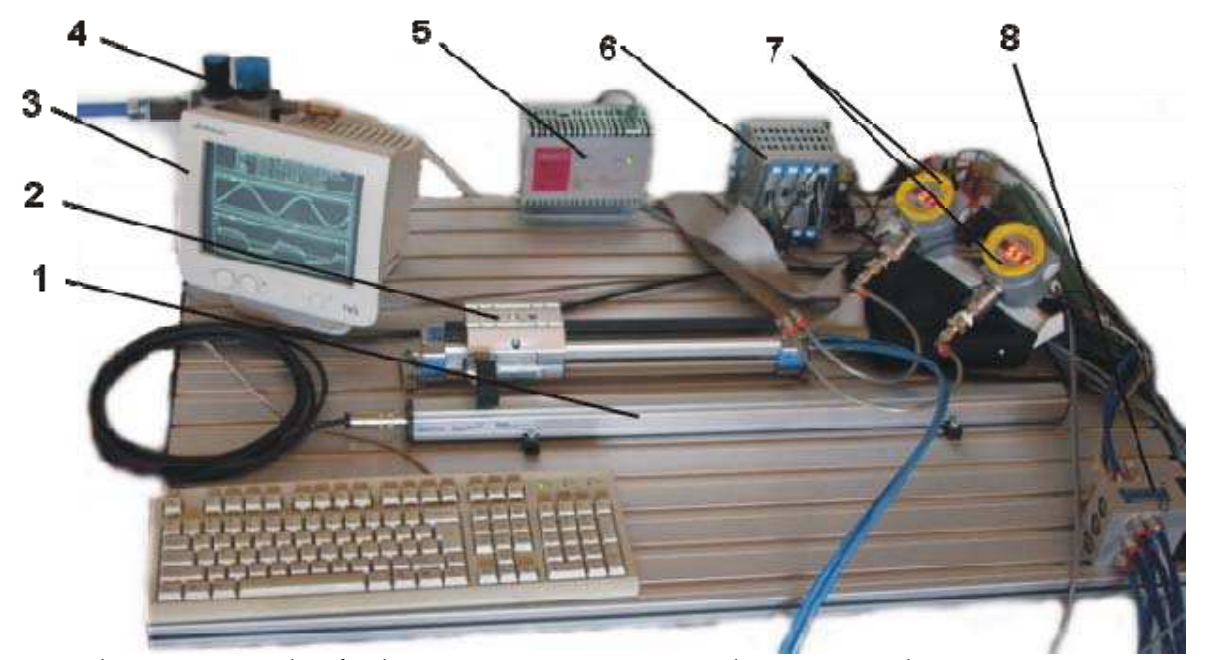

Fig. 4. The test stand of electro-pneumatic servo-drive control system: 1 - position transducer, 2 - rodless cylinder, 3 -xPC Target computer screen, 4 - pneumatic F.R. unit, 5 power supply, 6 - axis controller, 7 - pressure transducer, 8 - proportional control valve 


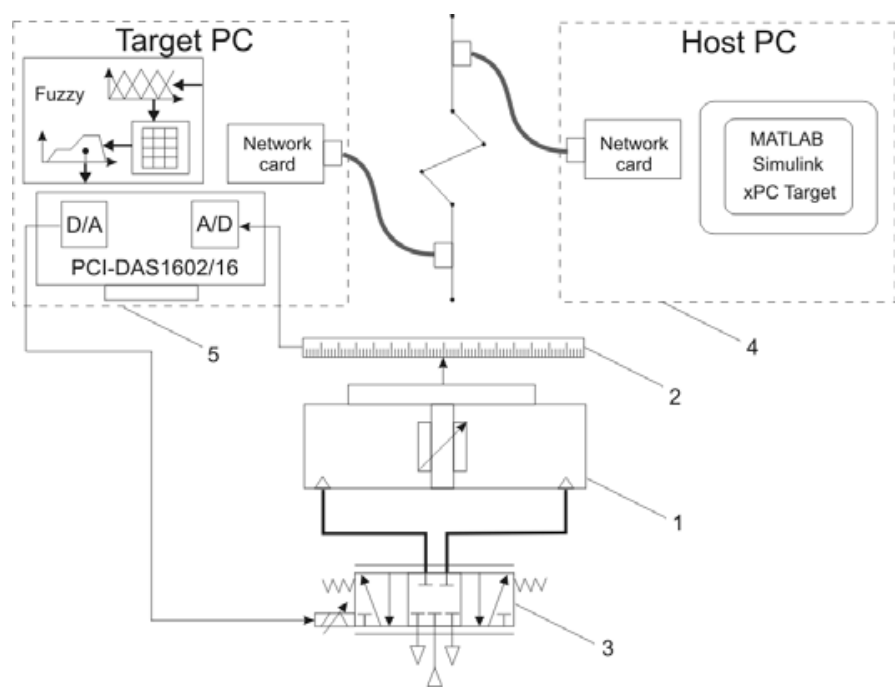

Fig. 5. The diagram of pneumatic servo-drive control system: 1 - rodless cylinder, 2 - position transducer, 2 - proportional control valve, 4 - computer Host, 5 - computer Target

The test stand consists of the following elements:

- $\quad$ pneumatic rodless cylinder (Festo DGPL-25-224) with piston diameter of $25 \mathrm{~mm}$ and stroke length of $224 \mathrm{~mm}$,

- $\quad$ proportional 5/3 directional control valve (Festo MPYE-5-1/8-HF-010-B) controlled by $0-10 \mathrm{~V}$ voltage of nominal flow rate $700 \mathrm{l} / \mathrm{min}$ and switching frequency $80 \mathrm{~Hz}$,

- non-contact micropulse displacement transducer (Balluff BTL5-A11-M0600-P-S32), analog output signal - voltage $0-10 \mathrm{~V}$,

- 16-bit measurement card (Measurement Computing Corporation AD/DA PCIDAS1602/16) with 8 analog inputs and 2 outputs,

- $\quad$ PC computers Host and Target.

The proposed pneumatic servo-drive control system contains two PC computers Target and Host where the first computer directly controls the pneumatic servo-drive and the second functions as the operator towards the direct control layer. In the computer marked as Host in Fig. 5 the software Matlab-Simulink together with xPC Target for rapid prototyping and real time control were installed. Target possesses an analog I/O card and a Real-Time $\mathrm{xPC}$ Target system which activates measurement data and controls pneumatic servo-drive. Host and Target communicate with each other by means of the TCP/IP protocol. Our work with the package for rapid prototyping consisted in construction and compilation of Simulink model, and sending the compiled model onto Target which together with analog I/O card and Real-Time xPC Target system functioned as real controller. Thanks to xPC Target software, the visualization of the analyzed control process was possible. The diagram showing how xPC Target works and communicates with Host computer is presented in Fig. 6. 


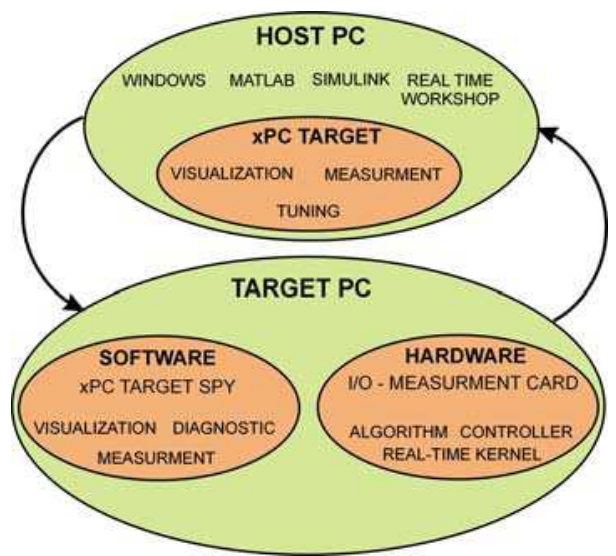

Fig. 6. Configuration of a link between Host and Target computers

In order to control pneumatic servo-drive, fuzzy PD controller was designed. The controller had two inputs $e(t)$ - position error and $\Delta e(t)$ - change of position error and one output $u(t)-$ voltage of coil valve obtained by means of Fuzzy Logic Toolbox of Matlab-Simulink package. The fuzzy controller operates on knowledge base containing IF-THEN rules (McNeill, 1994; Wolkenhauer, 2001; Kandel \& Langholz, 1991; Yager et al., 1994; Driankov et al., 1996; Spooner et al., 2002) for undetermined predicates and fuzzy control mechanism (Driankov et al., 1996):

$$
u(k)=F[e(k), e(k-1), \ldots, e(k-v), u(k-1), u(k-2), \ldots, u(k-v)]
$$

where: $u(k)$ - control signal describing relation between controller's input and output,

$e(k)$-position error between input signal $y_{0}(k)$ and output signal $y(k)$,

$k$-discrete time (sampling instant), $k=t / T$,

$t$-continuous time,

$T$-sampling period,

$v$ - parameter determining controller's order,

F - nonlinear function describing knowledge base of FLC (Driankov et al., 1996).

The FLC describes relations between the change of control signal $\Delta u(k)$ from one side and position error $e(k)$ and change of position error $\Delta e(k)=e(k)-e(k-1)$ from the other side. Thus fuzzy logic control relation for $v=1$ can be written as follows:

$$
\Delta u(k)=F[e(k), \Delta e(k)]
$$

The real output of $u(k)$ controller is obtained from the past control value $u(k-1)$ and its updating $\Delta u(k)$ as follows:

$$
u(k)=u(k-1)+\Delta u(k)
$$

The fuzzy controller of this type was proposed for the first time by Mamdani and Assilian, 
and was called fuzzy logic controller of Mamdani type (Driankov et al., 1996). The Control Law of Fuzzy PD Controller can be written as follows:

$$
u(k)=F[e(k), \Delta e(k)] .
$$

The inference algorithm transforms the Control Law (12) into non-fuzzy control algorithm which resembles the equation of traditional PD controller) (Wolkenhauer, 2001; Kandel \& Langholz, 1991; Driankov et al., 1996):

$$
u(k)=k_{P} \cdot e(k)+k_{D} \cdot \frac{\Delta e(k)}{T}=k_{P} \cdot e_{P}(k)+k_{D} \cdot e_{D}(k)^{\prime}
$$

where $k_{P}$ and $k_{D}$ represent gain of the proportional and derivative controller.

The rules for fuzzy PD controller are written as follows (Yager et al., 1994; Driankov et al., 1996):

IF $e_{P}(k)$ is <linguistic label $>\operatorname{AND} e_{D}(k)$ is <linguistic label $>$ THEN $u(k)<$ linguistic label $>$.

\begin{tabular}{|c|c|c|c|c|c|}
\hline$\Delta \mathrm{e} \backslash \mathrm{e}$ & $\mathrm{NB}$ & $\mathrm{NS}$ & $\mathrm{Z}$ & $\mathrm{PS}$ & $\mathrm{PB}$ \\
\hline $\mathrm{NB}$ & $\mathrm{NB}$ & $\mathrm{NB}$ & $\mathrm{NB}$ & $\mathrm{NB}$ & $\mathrm{NB}$ \\
\hline $\mathrm{NS}$ & $\mathrm{NB}$ & $\mathrm{NS}$ & $\mathrm{NS}$ & $\mathrm{NS}$ & $\mathrm{PS}$ \\
\hline $\mathrm{Z}$ & $\mathrm{NB}$ & $\mathrm{NS}$ & $\mathrm{Z}$ & $\mathrm{PS}$ & $\mathrm{PB}$ \\
\hline $\mathrm{PS}$ & $\mathrm{NS}$ & $\mathrm{PS}$ & $\mathrm{PS}$ & $\mathrm{PB}$ & $\mathrm{PB}$ \\
\hline $\mathrm{PB}$ & $\mathrm{PB}$ & $\mathrm{PB}$ & $\mathrm{PB}$ & $\mathrm{PB}$ & $\mathrm{PB}$ \\
\hline
\end{tabular}

Table 1. Knowledge base

The position error $e(k)$ changed in the range from $-3,7 \mathrm{~V}$ to $3,7 \mathrm{~V}$ which was the range of displacement of slide cylinder. For extreme values $\Gamma$ and $L$ sets were used which enabled to compensate the incomplete knowledge base for high amplitude values of $e(k)$ signal. Additionally, for position error $e(k)$ approaching zero a set of trapezoid type was used which enabled to determine the value of the assumed static error $2 \delta$ and to avoid oscillation around the zero error. For $\Delta e(k)$ signal the domain was determined in the range from $25 \mathrm{~V} / \mathrm{s}$ to $25 \mathrm{~V} / \mathrm{s}$ which corresponded to the range of displacement of slide cylinder. With the above assumptions taken into account the input signal $e(t)$ underwent fuzzyfication process with distribution of fuzzy sets while the input signal $\Delta e(t)$ underwent defuzzyfication process with distribution of fuzzy sets.

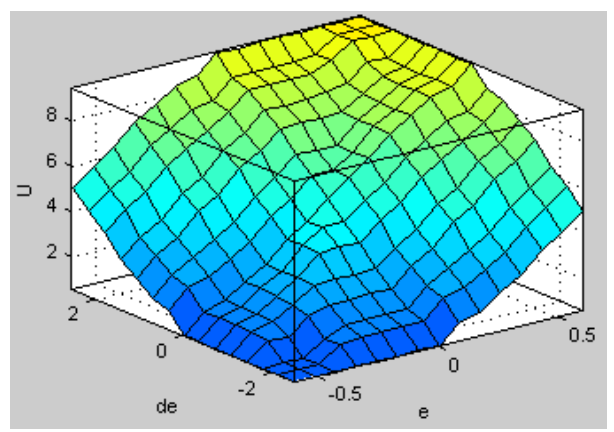

Fig. 7. Output control surface 
The measurements showed that flow rate characteristics of the proportional control valve are asymmetrical. Therefore, in the central position of spool valve where the voltage was $5 \mathrm{~V}$ the set of sigmoidal type shifted towards right (in accordance with the asymmetrical character of the valve) was used. For extreme fuzzy sets the sets of $\Gamma$ and $L$ type were applied as it was the case for input signals. Knowledge base contained 25 fuzzy rules included in table 1 . As the number of fuzzy rules and consequently the number of fuzzy sets was limited to 25 the sets were concentrated/ refined near zero error. This enabled smooth change of output signal near zero error, which implies, small jumps of the signal while passing from one fuzzy rule to the other. The surface control of the fuzzy controller is presented in Fig. 7. In the fuzzy inference process the firing degree of MIN type, fuzzy implication of MIN type and aggregation of particular outputs of the rule of MAX type were determined. In order to obtain crisp value the method of the Centre of Gravity was used.

\section{Results of simulations and experimental tests of electro-pneumatic servo- drive}

The performance control of the pneumatic servo-drive with fuzzy controller was checked by means of standard performance index including: settling time $t_{R}$, overshoot $\delta_{p}=y_{m}-y_{0}$, positioning error $e=y_{0^{-}} y(t) /$ as well as integral performance indexes: IAE, ITAE, ISE, ITSE (Takosoglu \& Dindorf, 2005). The additional performance criteria for follow-up control comprised absolute position error $\Delta x$ and absolute velocity error) $\Delta v$ :

$$
\begin{aligned}
& \Delta x=\frac{\sum_{i=1}^{N}\left|x_{0}[i]-x[i]\right|}{N}, \\
& \Delta v=\frac{\sum_{i=1}^{N}\left|v_{0}[i]-v[i]\right|}{N},
\end{aligned}
$$

where: $N$ - number of measuring points.

Simulations and experimental tests were conducted for the following parameters:

- $\quad$ pneumatic unit: $p_{z}=0,6 \mathrm{MPa}, T_{z}=293,15 \mathrm{~K}$,

- normal air: $T_{0}=293,15 \mathrm{~K}, p_{0}=0,6 \mathrm{MPa}, \rho_{0}=1,205 \mathrm{~kg} / \mathrm{m}^{3}, R=288 \mathrm{~N} \mathrm{~m} / \mathrm{kg} \cdot \mathrm{K}$, $\kappa=1,4$,

- proportional directional control valve: $C_{14}=C_{12}=C_{23}=C_{45}=1,462 \cdot 10^{-8} \mathrm{~m}^{4} \cdot \mathrm{s} / \mathrm{kg}, b_{14}$, $b_{12}, b_{23}, b_{45}=0,28$,

- $\quad$ pneumatic rodless cylinder: $A=4910^{-5} \mathrm{~m}^{2}, l_{0}=0,02 \mathrm{~m}, l=0,2 \mathrm{~m}, M=1 \mathrm{~kg}, f_{l}=250$ $\mathrm{N} \cdot \mathrm{s} / \mathrm{m}, k_{p}=3 \mathrm{~N} / \mathrm{Pa}, F_{k}=100 \mathrm{~N}, F_{p r}=200 \mathrm{~N}, v_{k}=0,1 \mathrm{~m} / \mathrm{s}$.

The simulation and experimental tests of pneumatic servo-drive were conducted mainly to check the operation of the designed control system with Fuzzy PD Controller during positioning of slide cylinder at various load mass. In accordance with the earlier assumption FLC with feedback caused by the displacement of slide cylinder was constructed. The displacement of pneumatic rodless cylinder slide was analyzed in the range $x=0-200 \mathrm{~mm}$, at velocity $v$ corresponding to $10 \%, 30 \%, 50 \%, 70 \%$ and $100 \%$ of maximum velocity $v_{\max }$ and mass load $m=0-16,5 \mathrm{~kg}$. The tasks to be performed by fuzzy controller included transpose control and follow-up control of pneumatic servo-drive. The 
input signals for transpose control were step signals and for follow-up control ramp and sin signals. The paper compares the selected results of simulation and experimental tests of position error displacement and velocity error of pneumatic servo-drive slide obtained in the same operating conditions and for the same input signal. In Fig. 8a and Fig. 8b the position, position error, velocity of cylinder slide obtained during transpose control for input signal of step type from the position $x=0 \mathrm{~mm}$ to the position $x=80 \mathrm{~mm}$ without mass load $(m=0)$ are compared.

a)

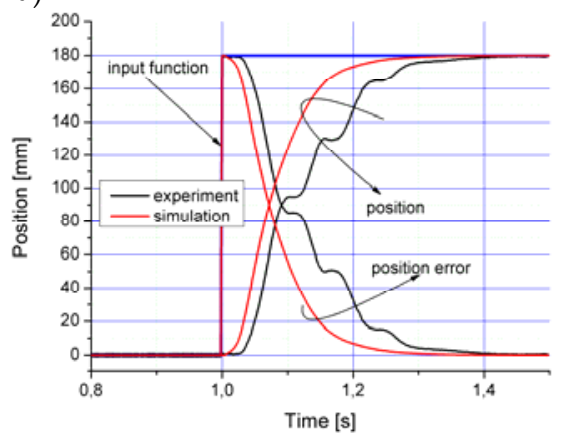

b)

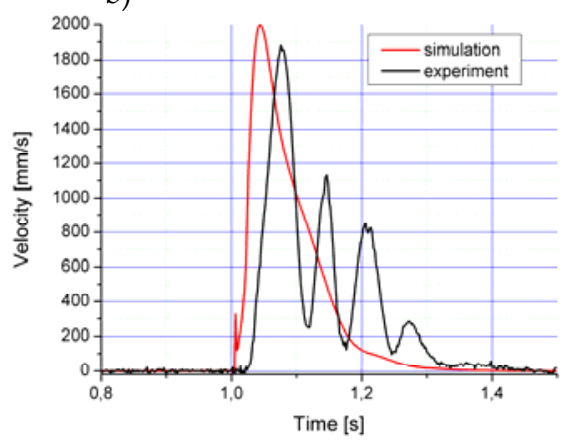

Fig. 8. Experimental and simulation results of position and position error a) and velocity b) of cylinder slide for input signal of step type

In Fig. 9a and Fig. 9b the position, position error, velocity and velocity error of cylinder slide obtained during follow-up control for input signal of ramp type from the position $x=12 \mathrm{~mm}$ to the position $x=180 \mathrm{~mm}$ with velocity $0,5 \mathrm{~m} / \mathrm{s}$ and mass load $m=3,67 \mathrm{~kg}$ are presented.

a)

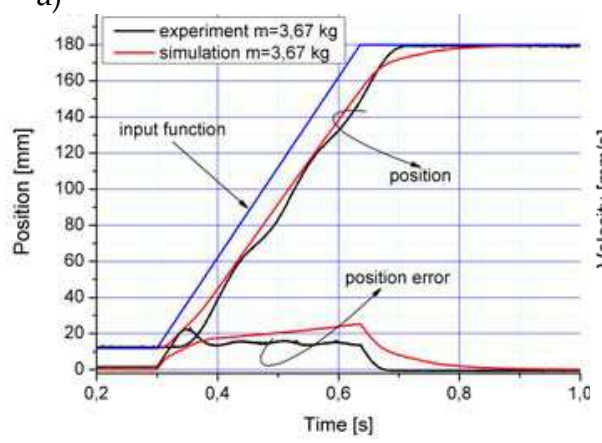

b)

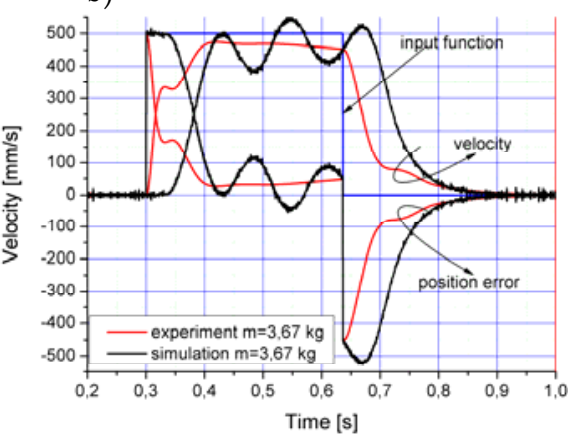

Fig. 9. Experimental and simulation results of position and position error a) and velocity b) of cylinder slide during follow-up control for input signal of ramp type

Fig. 10a and Fig. 10b shows the changes of absolute follow-up error of position signal and absolute follow-up error of velocity signal for follow-up control with input signal of ramp type. 
a)

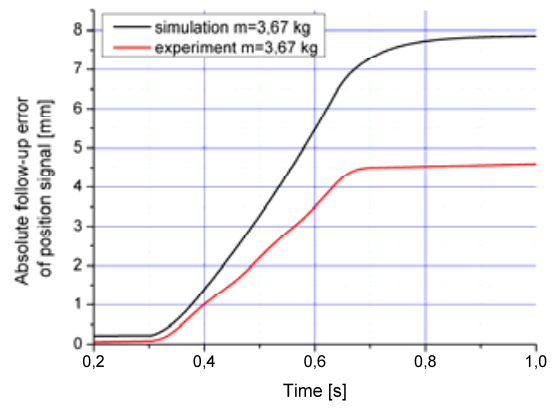

b)

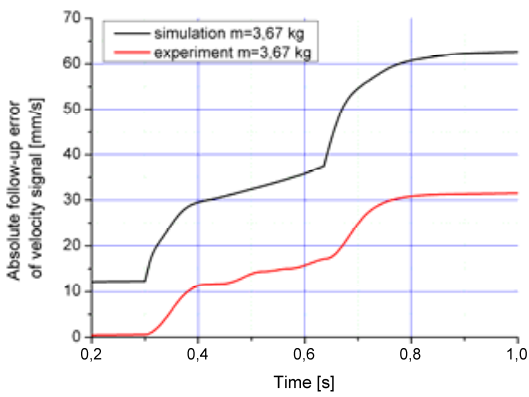

Fig. 10. Experimental and simulation results of absolute follow-up error of position signal $\Delta x$ a) and velocity signal $\Delta v$ b)

In Fig. 11a and Fig. 11b the position, position error, velocity and velocity error of pneumatic servo-drive cylinder slide for follow-up control with input signal of sin type and frequency $0,5 \mathrm{~Hz}$ without mass load $(m=0)$ is presented.

a)

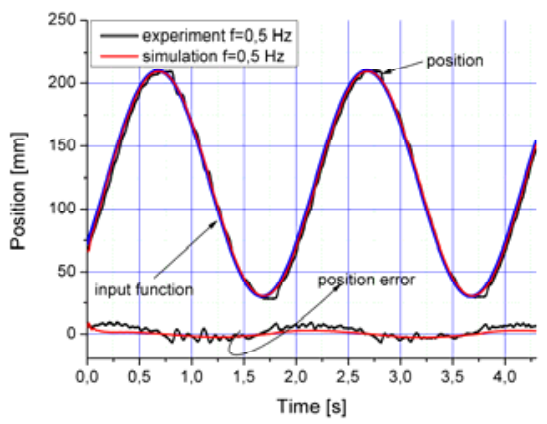

b)

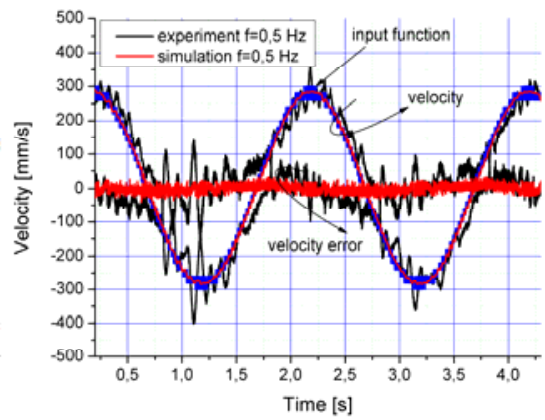

Fig. 11. Experimental and simulation results of position and position error a) and velocity b) of cylinder slide for $\sin$ input signal with frequency $0,5 \mathrm{~Hz}$

In Table 2 average performance indexes of fuzzy control obtained during experimental tests for transpose control with input signal of step type and follow-up control with input signal of ramp and sin type are compared.

\begin{tabular}{|c|c|c|c|c|c|c|c|}
\hline $\begin{array}{l}\mathrm{t}_{\mathrm{R}} \\
{[\mathrm{s}]}\end{array}$ & $\begin{array}{c}\delta \mathrm{P} \\
{[\mathrm{mm}]}\end{array}$ & IAE & ISE & ITAE & ITSE & $\begin{array}{l}\Delta \mathrm{x} \\
\mathrm{mm}\end{array}$ & $\begin{array}{c}\Delta \mathrm{v} \\
\mathrm{mm} / \mathrm{s}\end{array}$ \\
\hline \multicolumn{8}{|c|}{ Step input } \\
\hline 0,32 & 0,5 & 22,4 & 3301 & 3,8 & 490,1 & - & - \\
\hline \multicolumn{8}{|c|}{ Ramp input } \\
\hline 0,17 & 0,6 & 7,2 & 343,7 & 0,7 & 26,43 & 9,5 & 230,1 \\
\hline \multicolumn{8}{|c|}{ Sin input } \\
\hline- & - & 23,5 & 64,2 & 116,3 & 320,8 & 2,4 & 62,6 \\
\hline
\end{tabular}

Table 2. Performance indexes 
On the basis of the results of experimental research and simulations it may be concluded that the changes of position and velocity of pneumatic servo-drive cylinder slide obtained during experimental tests and simulations are convergent. From experimental research it follows that in the initial phase of the cylinder slide motion a small delay (approx. 0,5 s) in relation to input signal may be caused by break-away friction force in cylinder seals. During cylinder slide motion the correcting effect of FLC is clearly visible. In the next phase of cylinder slide motion the simulation and experimental results are almost the same. The runs of absolute follow-up error of position signal and velocity are also similar and the differences result from the quality of performance control. However, for bigger load mass $(m=3,67 \mathrm{~kg})$ the oscillatory motion of servo-motor slide is observed. The differences between simulation and experimental results are also caused by measurements noise in displacement transducer (for simulation tests the measurement noise was not taken into account). The designed fuzzy PD controller efficiently carries out the transpose and followup control of pneumatic servo-drive.

\section{Teaching/play-back control of electro-pneumatic servo-drive}

A teaching/play-back control system of electro-pneumatic servo-drive was constructed. Its input signal introduced manually by the operator by means of linear potentiometer was reproduced by pneumatic cylinder of pneumatic servo drive. In the teaching/play-back control system the software with PD Fuzzy PD Controller performing the task of teaching the pneumatic servo-drive motion was used. The suggested control system operates as follows: the operator by manually moving the linear potentiometer sets an optional motion trajectory and next the slide of rodless cylinder of pneumatic servo-drive reproduces this trajectory in real time. The view of the research stand of pneumatic servo-drive play-back control system is presented in Fig. 12 and its control diagram in Fig. 13. The research stand was constructed of the following elements:

- pneumatic rodless cylinder (Festo DGPL-25-224) with piston diameter of $25 \mathrm{~mm}$ and stroke length of $224 \mathrm{~mm}$,

- proportional 5/3 directional control valve (Festo MPYE-5-1/8-HF-010-B) of nominal flow rate $700 \mathrm{l} / \mathrm{min}$ and switching frequency $80 \mathrm{~Hz}$ controlled by analog voltage signal 0-10 V,

- non-contact micropulse displacement transducer (Balluff BTL5-A11-M0600-P-S32), analog output signal - voltage $0-10 \mathrm{~V}$,

- linear potentiometer (Festo MLO-POT-225-TLF), supply voltage 13-30 V, output voltage $0-10 \mathrm{~V}$, resistance $5 \mathrm{k} \Omega$, frequency $5 \mathrm{~Hz}-2 \mathrm{kHz}$,

- 16-bit measurement card (Measurement Computing Corporation AD/DA PCIDAS1602/16) with 8 inputs and 2 analog outputs,

- $\quad$ PC computers Host and Target.

During the experimental tests optional motion trajectories were set by means of linear potentiometer and motion trajectories reproduced by pneumatic servo-drive were recorded in real time. Each trajectory could be reproduced unlimited number of times in real time or recorded in the control program. The recorded motion trajectories were then reproduced by pneumatic servo-drive. 


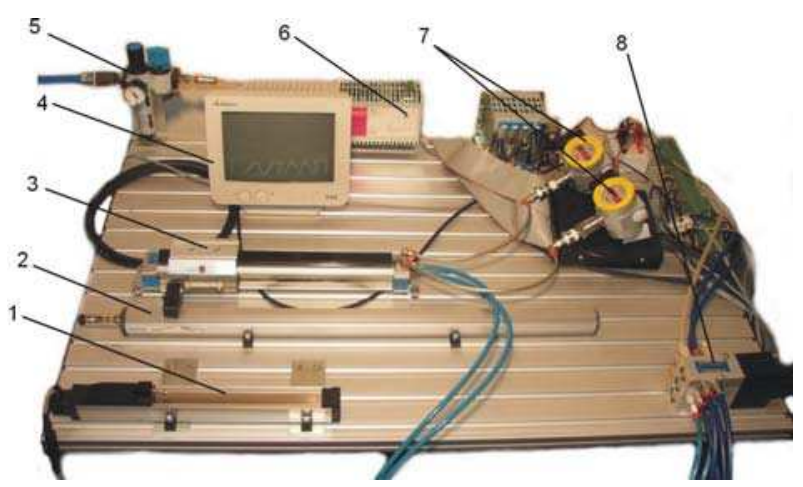

Fig. 12. The research stand of electro-pneumatic servo-drive motion teaching/play-back control system: 1 - linear potentiometer, 2 - position transducer, 3 - rodless cylinder, 4 Target computer screen, 5 - pneumatic F.R. unit, 6 - power supply, 7 - pressure transducer, 8 - proportional control valve

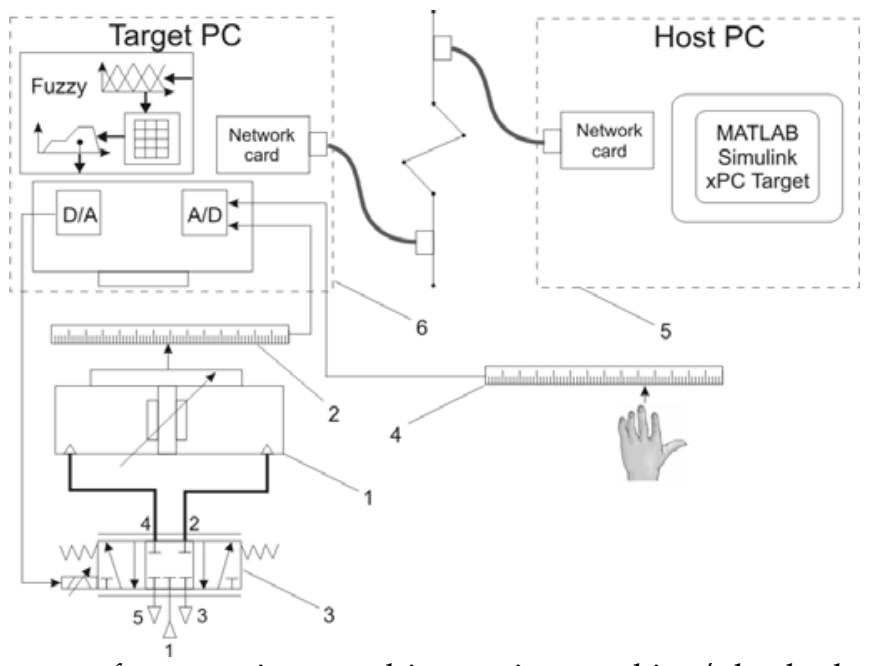

Fig. 13. The diagram of pneumatic servo-drive motion teaching/play-back control system: 1 - rodless cylinder, 2 - position transducer, 2 - proportional control valve, 4 - linear potentiometer, 5 - Host computer , 6 - Target computer

The quality of teaching/play-back control with FLC was checked by means of standard performance indexes including position error) $\delta_{x}=\mid x_{0}-x(t) /$, velocity error $\delta_{v}=t_{0}-v(t) /$ and acceleration error $\delta_{a}=a_{0}-a(t) /$. In follow-up control the additional quality criteria comprised: absolute error signal $\Delta x(t)$ of velocity $\Delta v(t)$ and acceleration position $\Delta a(t)$ :

$$
\Delta x(t)=\frac{\sum_{i=1}^{N}\left|x_{0}[i]-x[i]\right|}{N},
$$




$$
\begin{aligned}
& \Delta v(t)=\frac{\sum_{i=1}^{N}\left|v_{0}[i]-v[i]\right|}{N}, \\
& \Delta a(t)=\frac{\sum_{i=1}^{N}\left|a_{0}[i]-a[i]\right|}{N},
\end{aligned}
$$

where: $N$ - number of measurement points.

The results of experimental tests on displacement, position error, velocity and velocity error as well as acceleration and acceleration error of cylinder slide of pneumatic servo-drive during reproduction of optional motion trajectory are presented in Fig. 14.
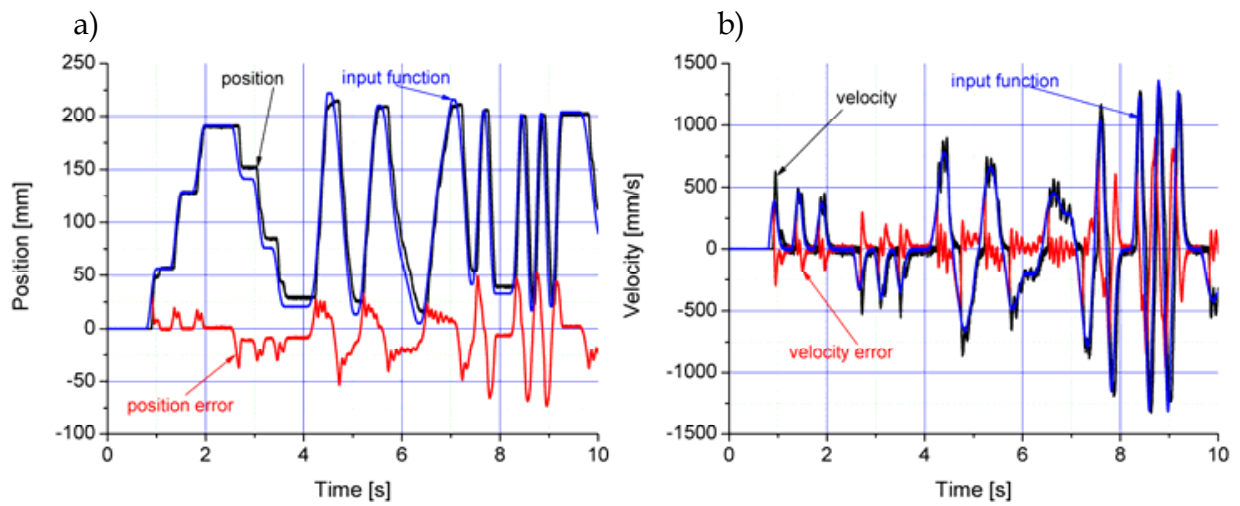

c)

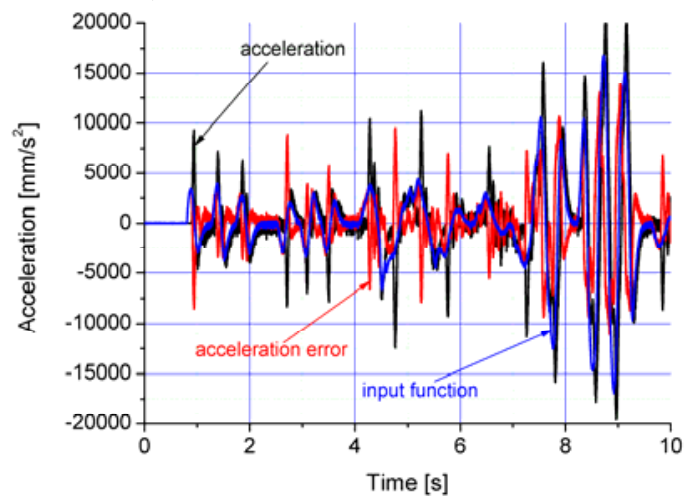

Fig. 14. Experimental results of position a), velocity b) and acceleration c) of cylinder slide

The changes of absolute follow-up error signal of displacement, velocity and acceleration of pneumatic servo-drive cylinder slide are presented in Fig. 15. 
a)

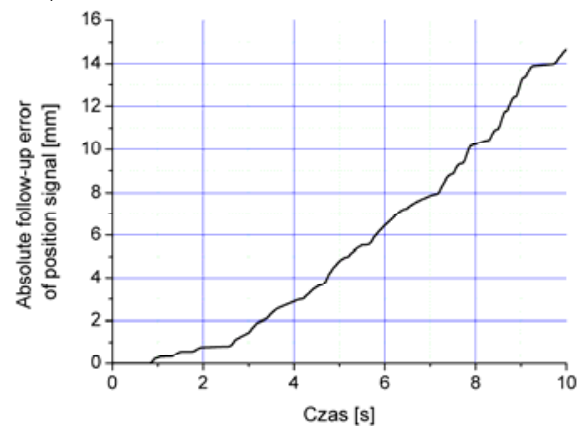

b)

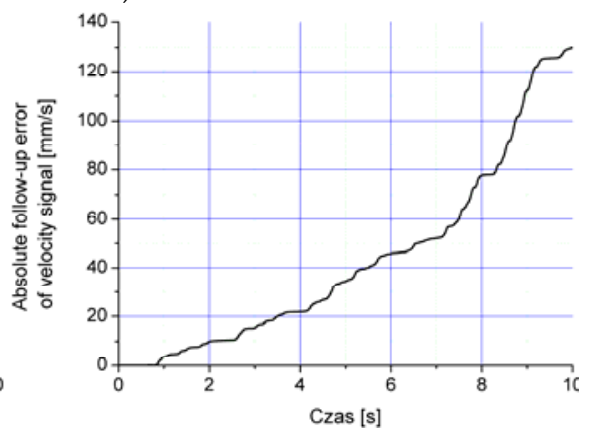

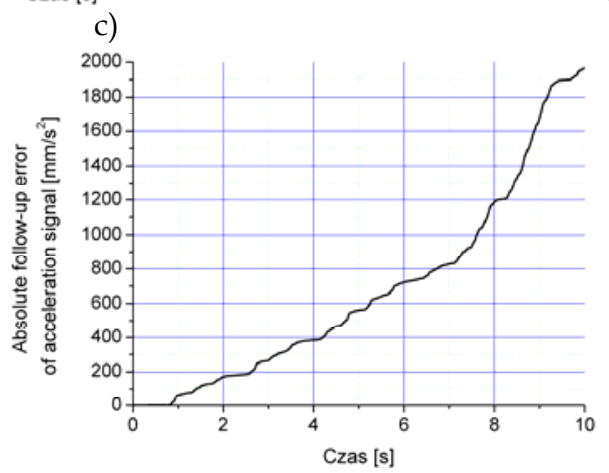

Fig. 15. Experimental values of absolute follow-up error signal of position a), velocity b) and acceleration c)

\section{Prototype of electro-pneumatic parallel 3-UPRR tripod manipulator}

In the Division of Mechatronics (Kielce University of Technology, Poland) a prototype of pneumatic translational parallel manipulator (PTPM) of tripod kinematic structure was constructed (Dindorf et al., 2005; Laski \& Dindorf, 2007). The prototype of tripod parallel manipulator with Festo servopneumatic precision positioning systems is presented in Fig. 1a. The manipulator possesses a supporting structure, fixed base, moving platform and three pneumatic linear motions (servopneumatic axis). Each servopneumatic axis consists of: rodless pneumatic cylinder type DGPIL-25-600 with integral feedback transducer (built-in 'Temposonic' encoders for continual positioning feedback to the master control unit), 5/3 servopneumatic valve (proportional directional control valve) type MPYE-5-1/8-HF-010B, axis interface type SPC-AIF, positioning axis sub-controller type SPC-200 (the use of a subcontroller card permits control of up to four axes) and Ethernet/Can Bus interface. According to the systematics the prototype of 3-DoF pneumatic translational parallel manipulators is of 3-UPRR kinematic structure (Fig. 1b). Each of the three identical closedloop chains of the manipulator consists of serial kinematic chains: universal cardan joint (U), prismatic joint $(\mathrm{P})$, formed by a rodless pneumatic cylinder and two revolute joints $(2 \mathrm{R})$ formed after universal cardan had been parted. The slide of rodless cylinder was connected with fixed base by means of articulated joints of $U$ cardan and the end cap of cylinder were 
connected by revolute joint $\mathrm{R}$ to the moving platform. The second revolute joint $\mathrm{R}$ was placed in tool center point (TCP) of the moving platform. The presented construction of the parallel manipulator ensures parallel position of the moving platform to the fixed base for optional position of pneumatic cylinder. The kinematic structure of a new prototype of 3UPRR pneumatic parallel manipulator is an interesting solution expanding the architecture of parallel manipulators, type 3-DoF TPM.

a)

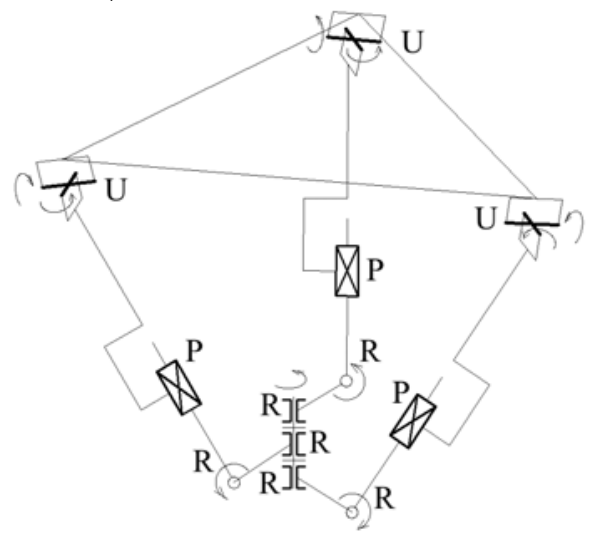

b)

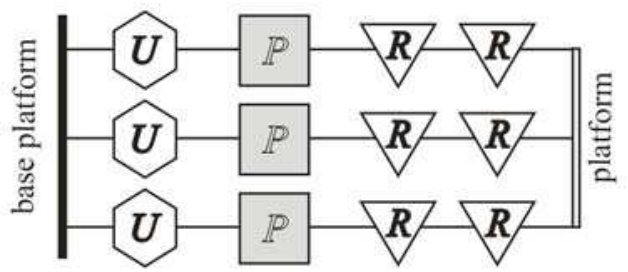

Fig. 16. Pneumatic translational parallel manipulator: a) prototype, b) kinematics scheme

\section{Model research of electro-pneumatic parallel 3-UPRR tripod manipulator}

CAD software (SolidWorks, Mechanical Desktop, Solid Edge) commonly used by constructors enables designing solid models of complex mechanisms of parallel kinematics. A solid model of 3-UPRR pneumatic parallel manipulator obtained by SolidWorks is presented in Fig. 17a. To record geometric and kinematic relations holding for pneumatic parallel manipulator of 3-UPRR kinematics its kinematic model presented in Fig. 17b was used.
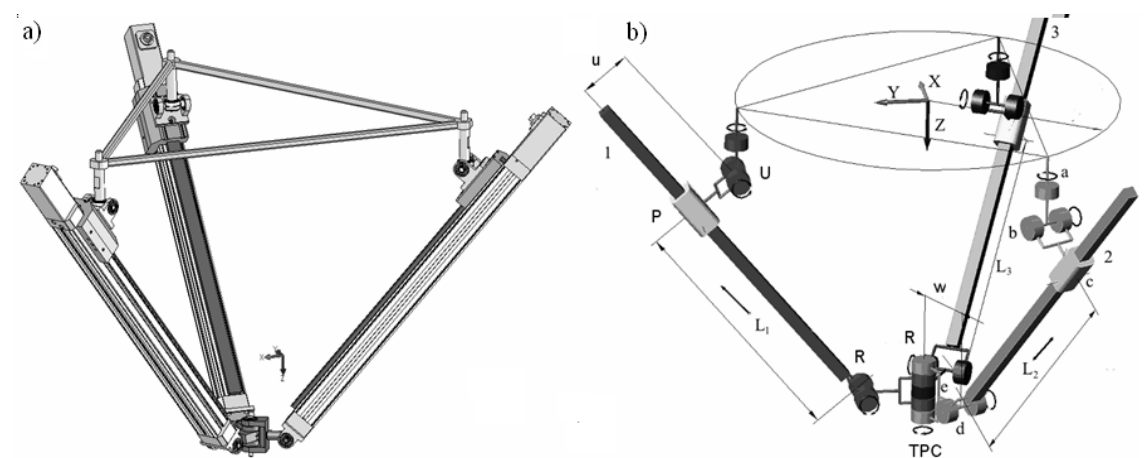

Fig. 17. Solid model a) of pneumatic parallel manipulator b) and kinematic model 
By means of Dynamic Designer Motion, which possesses graphic interface SolidWorks the simulation of pneumatic parallel manipulator's motion was conducted. In order to simulate the manipulator's motion it was necessary to define the basic parameters, kinematic joints and motion restrictions. For solid model a few composite relations were defined which enabled assigning them kinematic joints. In some cases it was necessary to introduce joints describing the construction's stiffness. Basing upon material properties and the shape of particular solids the mass of the solid model was calculated. The simulation of manipulator's parallel mechanism motion was saved in avi format. The simulations conducted on a solid model aimed at position analysis of TCP point of the moving platform. The position of TCP point results from linear motion of pneumatic rodless cylinder, independently controlled by servo-valves.

Since the application of SolidWorks in modeling kinematics and dynamics of parallel manipulators is restricted further simulation was carried out by means of SimMechanics library of Matlab-Simulink package. The library enables the construction of complex mechanisms of parallel manipulators excluding mathematical descriptions of their kinematics and dynamics. The kinematic model of 3-UPRR manipulator obtained by means of SimMechanics library is presented as block diagram in Fig. 18.

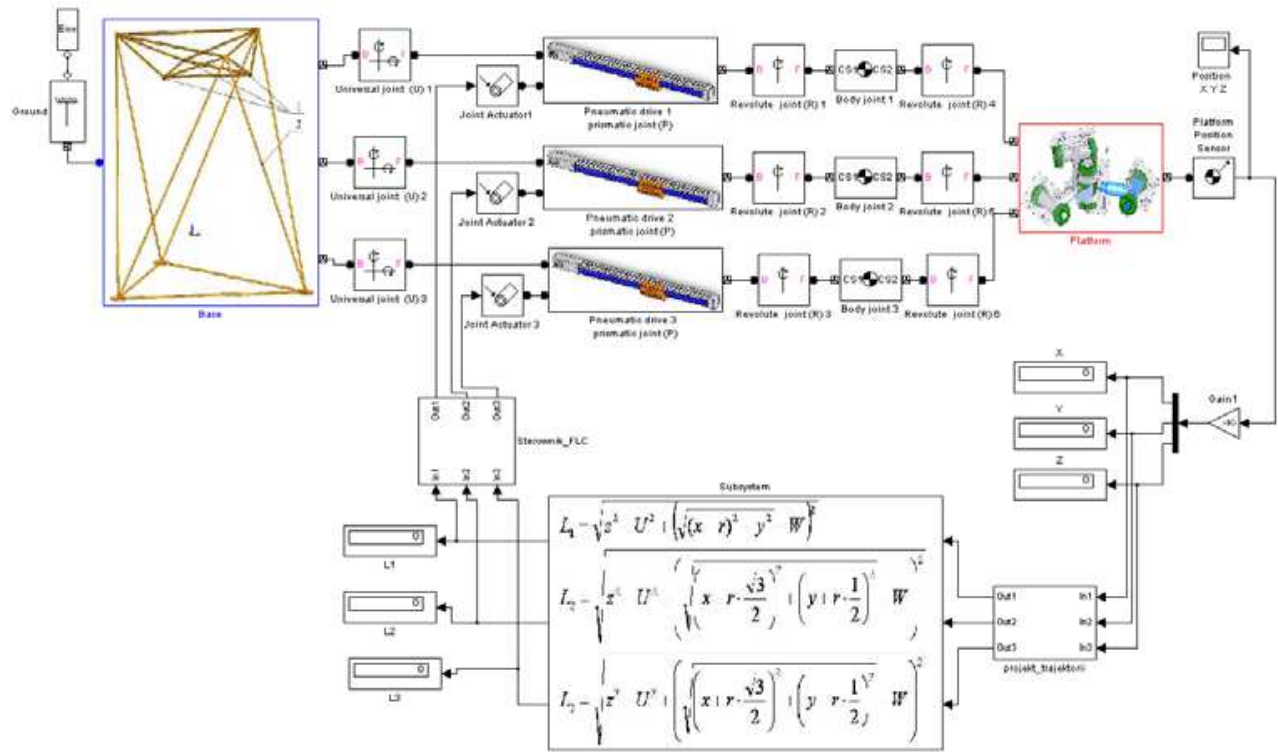

Fig. 18. The block-diagram of kinematic model of electro-pneumatic parallel tripod manipulator

On the basis of this block-diagram the equivalent model of pneumatic parallel manipulator was worked out (Fig. 19a). In simulations based upon SimMechanics library an equivalent model of pneumatic tripod manipulator with its spatial orientation indicated was constructed. In SimMechanics library all the solid elements of the manipulator were described by substitute geometry by means of ellipsoids and assigned both masses and inertial tensors. In Matlab-Simulink environment tripod-based parallel kinematic 
manipulator was connected with its control system. The equivalent model retains kinematic joints and spatial orientation defined in solid model in SolidWorks. To create the equivalent model it was necessary to define the gravity centre of solids in central and local coordinates. The kinematic model was used to TCP trajectory analysis. The TCP trajectory of pneumatic parallel manipulator in Cartesian coordinates is shown in Fig. 19b.

The research on the model was supplemented with the analysis of servo-pneumatic axis control applied in 3-UPRR pneumatic parallel manipulator. By means of simulation model and experimental setup transpose control, follow-up control, trajectory motion control and fuzzy control of single servo-pneumatic axis were investigated (Takosoglu 2005). To control the servo-pneumatic axis a controller FLC (Fuzzy Logic Controller) of PD type was used. In fuzzyfication process conditionally firing rules of type MIN, implication operator of type MIN and aggregation of output rules of type MAX were employed. Twenty five FLC's knowledge base forming FLC's control surface were used. To obtain fuzzy output value the center of gravity function (COG) was used.

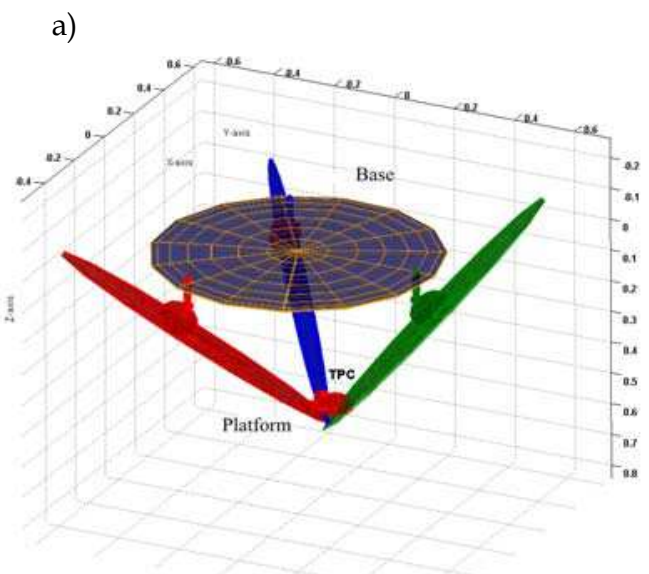

b)

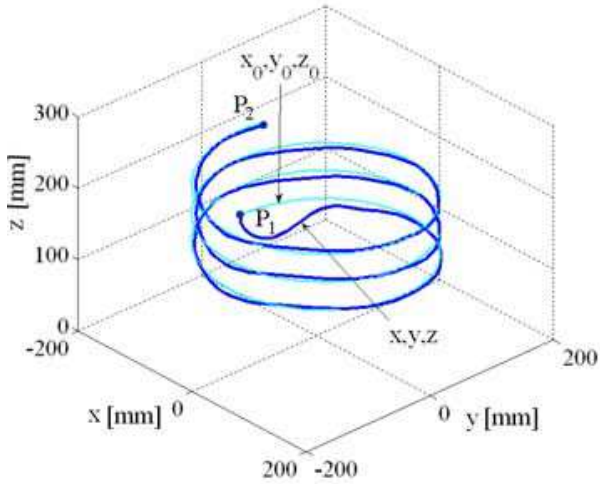

c)

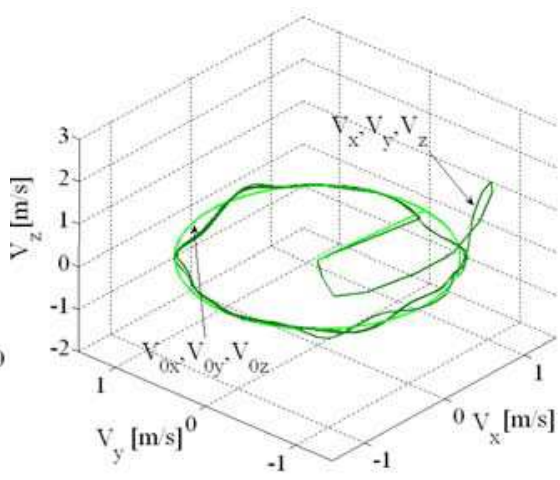

Fig. 19. The equivalent model a), TCP trajectory b) and velocity of electro-pneumatic parallel tripod manipulator 
Application of FLC controller improved dynamics and positioning accuracy of servopneumatic axis and eliminated disturbances in its control system. On the basis of the research the control of servopneumatic axis using fuzzy logic for trajectory planning of parallel manipulators can be established. The research proves applicability of fuzzy logic in control of pneumatic parallel manipulators with different kinematic chain structure. Advanced servopneumatic positioning contributes to a new generation of parallel manipulators. Especially parallel manipulators actuated by servopneumatic axis enable realization of very fast pick and place in 3-D workspace.

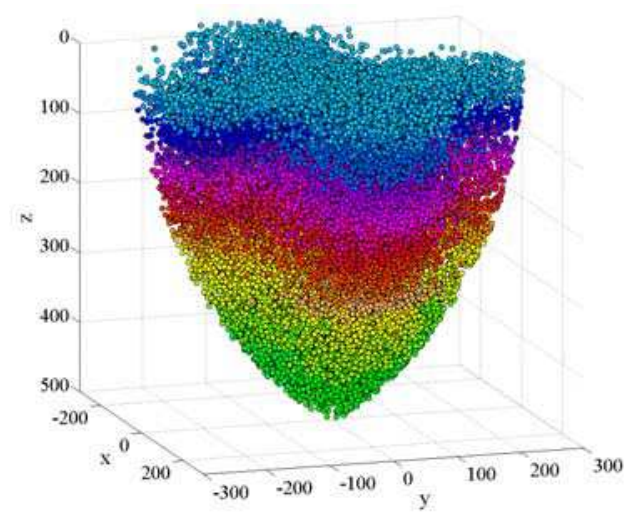

Fig. 20. Working space of pneumatic parallel manipulator

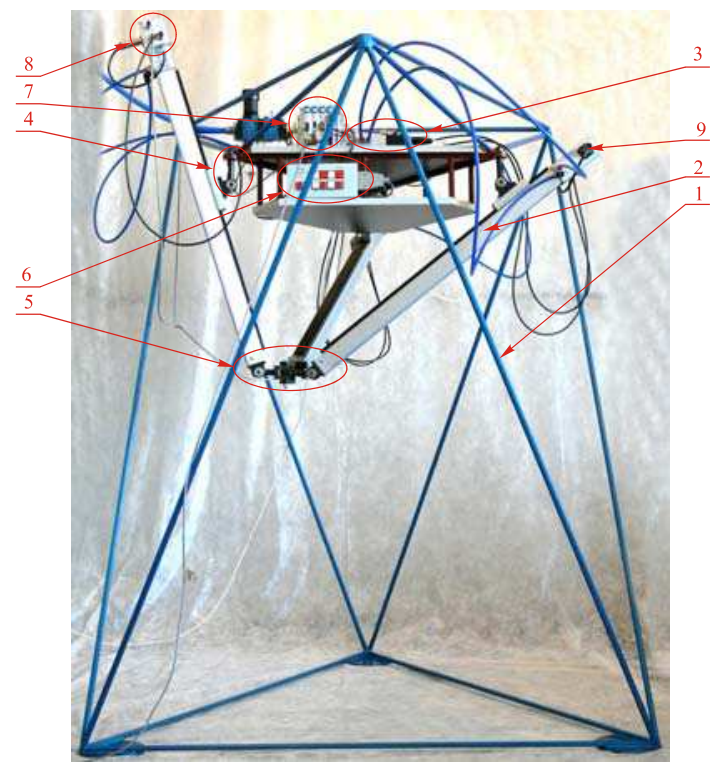

Fig. 21. Component elements of electro-pneumatic parallel tripod manipulator: 1 - basis, 2 cylinder, 3 - servo-valve 5/3, 4 - universal Cardan joints, 5 - working platform, 6 - control panel, 7 - the driver the SPC -200, 8 - the interface of communicate the network SPC AIF MTS, 9 - the connector communication 


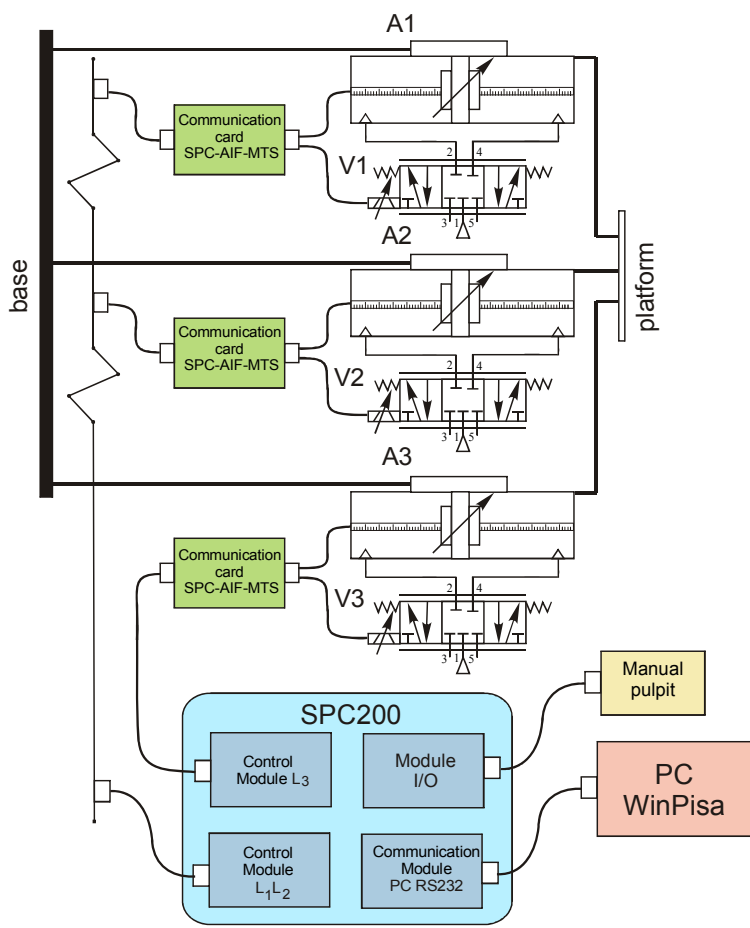

Fig. 22. Schematic diagram of pneumatic servo-drive parallel manipulator

\section{Conclusion}

The results of simulation and experimental tests conducted for pneumatic servo-drive with FLC are presented. For positioning control of pneumatic servo-drive a fuzzy PD controller was designed and constructed by means of xPC Target software of Matlab-Simulink package for rapid prototyping and hardware-in-the-loop simulation. The non-linear simulation model of pneumatic servo-drive was constructed and used to tune fuzzy PD controller by means of Fuzzy Logic Toolbox of Matlab-Simulink package. The research stand consisted of two computers: Host and Target with the first of them being the master and performing the function of the operator towards the direct control layer and the second directly controlling the pneumatic servo-drive. The fuzzy logic PD controller enables precise positioning of pneumatic servo-drive with the precision specified for industrial manipulators. A lot of simulation and experimental tests were carried on pneumatic servodrive with fuzzy controller which was used for its transpose and follow-up control. The designed fuzzy system is efficient, stable and resistant to disturbances and can be applied in any configurations of pneumatic servo-drive without necessity to tune the regulator, apply signal filtration or additional operations in track control or restrict the signals generated.

The analysis of displacement and velocity characteristics show that their runs are similar. The position delay (approx. 0,5 s) on the experimental characteristics in relation to input signal is caused by break away friction force. In the process of servo cylinder's motion correcting effect of FLC leading to rapid minimization of displacement error is observed. In 
the next motion phase the simulation and experimental characteristics are almost the same. The runs of absolute follow-up error of position signal and velocity are also similar and the differences result from the quality of performance control. Some oscillations of transient response most probably caused by time delay, stick-slip effect in seals and strip of pneumatic rodless cylinder are observed. In the the mathematical model of the cylinder Stribeck friction force was taken into account. Including LuGre (Lund-Grenoble) model in the friction would considerably improve the simulation results but would also make the numerical solutions of simulation model much more complex. It seems that other simplifications of mathematical model do not influence the difference between simulation and experimental results. It should be noted however, that differences between simulation and experimental results are affected by measurement noise in displacement transducer. In simulations measurement noise was not taken into account.

The teaching/play-back control system using fuzzy logic control was constructed and practically applied in various servo-pneumatic systems used in production automation. Basing upon the presented control/teaching/play-back system the prototype of physiotherapy manipulator facilitating the movement of hand and leg is being constructed (Takosoglu, 2005).

The research on models shortened the construction process of the prototype of 3-UPRR electro-pneumatic parallel manipulator. The analysis of geometric and kinematic properties of the prototype resulted in numerous changes and modifications of its construction made in order to obtain the biggest workspace without collision with pneumatic linear motion. The research enabled drawing the conclusions on construction optimization and control of 3-UPRR pneumatic parallel manipulator. Our further research will focus on dynamic analysis and dynamic synthesis as well as on 3-UPRR pneumatic parallel manipulator's programming. The presented novel 3-UPRR parallel mechanism will find its application in manufacturing manipulators and rehabilitation manipulators. Thanks to application of parallel kinematics in construction of electropneumatic manipulators higher rigidity of the whole pneumatic structure has been obtained and both positioning precision and dynamic properties have been improved. The closed mechanical chains make the dynamics of parallel manipulators coupled and highly nonlinear.

\section{References}

Bucher R.; Balemi S. (2006). Rapid controller prototyping with Matlab/Simulink and Linux. Control Engineering Practice, Vol. 14, (May 2006), pp. 185-192

Dindorf R.; Laski P.; Takosoglu J. (2005). Control of electro-pneumatic 3-DOF parallel manipulator using fuzzy logic. Hydraulika a Pneumatyka, Vol. 1-2, (January 2005), pp. 56-59, ISSN 1335-5171

Dindorf R.; Laski P.; Takosoglu J. (2008). Solid modeling of pneumatic elements and driving systems, Book of Extended Abstracts of the 12th International Scientific Seminar on Developments in Machinery Design and Control, pp.27-28, ISBN 978-83-87982-08-9, Cerveny Klastor, September 2008, University of Technology and Live Sciences, Bydgoszcz

Dindorf R.; Takosoglu J. (2005). Analysis of pneumatic servo-drive control system using fuzzy controller. Pneumatyka Vol. 1 (January-February 2005), pp. 51-53, ISSN 14266644 
Driankov, D.; Hellendoorn, H.; Reinfrank, M. (1996) An introduction to fuzzy control, WNT, ISBN 83-204-2030-x, Warsaw

Kandel A. (1991). Fuzzy Expert Systems, CRC Press, Inc., ISBN 08-493-4297-x, Boca Raton, Florida

Kandel A.;, Langholz G. (1993). Fuzzy Control Systems, CRC Press, Inc., ISBN 08-493-4496-4, Boca Raton, Florida

Laski P.; Dindorf R. (2007). Prototype of pneumatic parallel manipulator. Hydraulika a Pneumatyka, Vol. 1, (January 2007), pp. 22-24, ISSN 1335-5171

Laski P.; Dindorf R. (2007). Prototyping of tripod-type pneumatic parallel manipulatore, Book of Extended Abstracts of the 11 th International Scientific Seminar on Developments in Machinery Design and Control, pp.49, ISBN 83-87982-42-3, Cerveny Klastor, September 2007, University of Technology and Live Sciences, Bydgoszcz

McNeill F. M. (1994). Fuzzy Logic A Practical Approach, Academic Press Professional, Inc., ISBN 0-12-485965-8, Boston

Merlet J. P. (2006). Parallel robots, Springer, ISBN 1-4020-4132-7, Dordrecht

Murray R. M.; Li Z.; Sastry S. S. (1994). A mathematical introduction to robotic manipulation, CRC Press, Inc., ISBN 0-8493-7981-4, Boca Raton, Florida

Renn J. C.; Liao C. M. (2004). A study on the speed control performance of a servopneumatic motor and the application to pneumatic tools. The International Journal of Advanced Manufacturing Technology, Vol. 23, (February 2004), pp. 572-576, ISSN 1433-3015

Sandler B. Z. (1999). Robotics: Designing the mechanisms for automated machinery, Academic Press, ISBN 0-12-618520-4, California

Schulte H.; Hahn H. (2004). Fuzzy state feedback gain scheduling control of servopneumatic actuators. Control Engineering Practice, Vol. 12, (May 2004), pp. 639-650

Situm Z.; Pavkovic D.; Novakovic B. (2004). Servo pneumatic position control using fuzzy PID gain scheduling. Transactions of the ASME Journal of Dynamic Systems, Measurement, and Control, Vol. 126, (June 2004), pp. 376-387

Spooner J. T.; Maggiore M.; Ordonez R.; Passino K. M. (2002). Stable adaptive control and estimation for nonlinear systems: Neural and fuzzy approximator techniques. John Wiley \& Sons, Inc., ISBN 0-471-22113-9, New York

Takosoglu J.; Dindorf R. (2005). Fuzzy control of pneumatic servo-drive. Proceedings of the 15 th National Conference of Automatics, pp. 117-120, ISBN 83-89475-01-4, Warsaw, June 2005, Systems Research Institute Polish Academy of Science, Warsaw

Takosoglu J.; Dindorf R. (2006). Rapid prototyping a fuzzy control of electro-pneumatic servo-drive in real time. Scientific Bulletin of the College of Computer Science, Vol. 5, No. 1, pp.57-70,

Takosoglu J.; Dindorf R. (2007). Positioning and teaching/play-back fuzzy control of electropneumatic servo-drive in real time, Proceedings of the $7^{\text {th }}$ European Conference of Young Research and Science Workers Transcom 2007, pp. 199-202, ISBN 978-80-8070694-4, Zilina, June 2007, University fo Zilina, Zilina

Takosoglu J.; Dindorf R. (2007). Positioning control and teaching/play-back control of electro-pneumatic servo-drive, Book of Extended Abstracts of the 11 th International Scientific Seminar on Developments in Machinery Design and Control, pp.89, ISBN 8387982-42-3, Cerveny Klastor, September 2007, University of Technology and Live Sciences, Bydgoszcz 
Takosoglu, J. (2005). Analysis and synthesis of pneumatic multi-axis servo-drive control system using fuzzy controller, Dissertation, Kielce University of Technology, Kielce

Takosoglu, J. E.; Dindorf, R. F.; Laski, P. A. Rapid prototyping of fuzzy controller pneumatic servo-system. The International Journal of Advanced Manufacturing Technology, Vol. 40, No. 3-4, January 2008, pp. 349-361, ISSN 0268-3768

Takosoglu, J.; Dindorf, R. (2005) Fuzzy control of pneumatic servo-drive, Proceedings of the $15^{\text {th }}$ National Conference of Automatics. Systems Research Institute Polish Academy of Science, pp. 117-120, ISBN 83-89475-01-4, Warsaw, June 2005, Systems Research Institute Polish Academy of Science, Warsaw

Tsai L. W. (1999). Robot analysis: The mechanics of serial and parallel manipulators, John Wiley \& Sons, Inc., ISBN 0-471-32593-7, New York

Wolkenhauer O. (2001). Fuzzy mathematics in systems theory and data analysis, John Wiley \& Sons, Inc., ISBN 0-471-22434-0, New York

Yager, RR.; Filev, DP. (1994) Essentials of fuzzy modeling and control, WNT, ISBN 83-204-19093, Warsaw

Zhu Y. (2006). Control of pneumatic systems for free space and interaction tasks with system and environmental uncertainties, Dissertation, Vanderbilt University, Nashville, Tennessee 


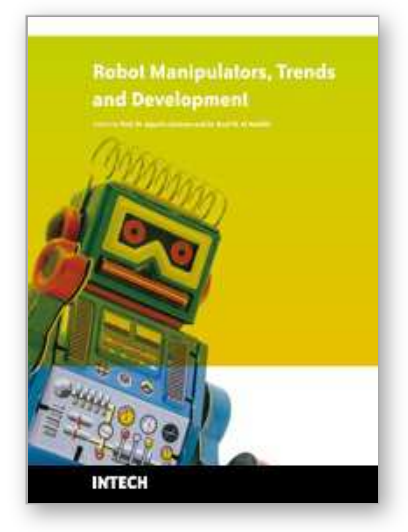

\author{
Robot Manipulators Trends and Development \\ Edited by Agustin Jimenez and Basil M Al Hadithi
}

ISBN 978-953-307-073-5

Hard cover, 666 pages

Publisher InTech

Published online 01, March, 2010

Published in print edition March, 2010

This book presents the most recent research advances in robot manipulators. It offers a complete survey to the kinematic and dynamic modelling, simulation, computer vision, software engineering, optimization and design of control algorithms applied for robotic systems. It is devoted for a large scale of applications, such as manufacturing, manipulation, medicine and automation. Several control methods are included such as optimal, adaptive, robust, force, fuzzy and neural network control strategies. The trajectory planning is discussed in details for point-to-point and path motions control. The results in obtained in this book are expected to be of great interest for researchers, engineers, scientists and students, in engineering studies and industrial sectors related to robot modelling, design, control, and application. The book also details theoretical, mathematical and practical requirements for mathematicians and control engineers. It surveys recent techniques in modelling, computer simulation and implementation of advanced and intelligent controllers.

\title{
How to reference
}

In order to correctly reference this scholarly work, feel free to copy and paste the following:

Jakub E. Takosoglu, Ryszard F. Dindorf and Pawel A. Laski (2010). Fuzzy Logic Positioning System of ElectroPneumatic Servo-Drive, Robot Manipulators Trends and Development, Agustin Jimenez and Basil M Al Hadithi (Ed.), ISBN: 978-953-307-073-5, InTech, Available from: http://www.intechopen.com/books/robotmanipulators-trends-and-development/fuzzy-logic-positioning-system-of-electro-pneumatic-servo-drive

\section{INTECH}

open science | open minds

\author{
InTech Europe \\ University Campus STeP Ri \\ Slavka Krautzeka 83/A \\ 51000 Rijeka, Croatia \\ Phone: +385 (51) 770447 \\ Fax: +385 (51) 686166 \\ www.intechopen.com
}

\author{
InTech China \\ Unit 405, Office Block, Hotel Equatorial Shanghai \\ No.65, Yan An Road (West), Shanghai, 200040, China \\ 中国上海市延安西路65号上海国际贵都大饭店办公楼 405 单元 \\ Phone: +86-21-62489820 \\ Fax: +86-21-62489821
}


(C) 2010 The Author(s). Licensee IntechOpen. This chapter is distributed under the terms of the Creative Commons Attribution-NonCommercialShareAlike-3.0 License, which permits use, distribution and reproduction for non-commercial purposes, provided the original is properly cited and derivative works building on this content are distributed under the same license. 